\title{
Image findings of cranial nerve pathology on [18F]-2- deoxy-D-glucose (FDG) positron emission tomography with computerized tomography (PET/CT): a pictorial essay
}

\author{
Osama A. Raslan ${ }^{1 *}$, Razi Muzaffar ${ }^{1}$, Vilaas Shetty ${ }^{2}$ and Medhat M. Osman ${ }^{1}$
}

\begin{abstract}
This article aims to increase awareness about the utility of ${ }^{18} \mathrm{~F}$-FDG-PET/CT in the evaluation of cranial nerve (CN) pathology. We discuss the clinical implication of detecting perineural tumor spread, emphasize the primary and secondary ${ }^{18} \mathrm{~F}$-FDG-PET/CT findings of CN pathology, and illustrate the individual ${ }^{18} \mathrm{~F}$-FDG-PET/CT CN anatomy and pathology of 11 of the 12 CNs.
\end{abstract}

\section{Background}

Conventional CT and MRI have been the imaging modalities of choice for evaluation of cranial nerve $(\mathrm{CN})$ pathology. However, $\mathrm{CN}$ pathology can also be detected on $[18 \mathrm{~F}]$-2- deoxy-D-glucose (FDG) positron emission tomography with computerized tomography (PET/CT) imaging [1-3]. As FDG PET/CT is increasingly being used for oncologic imaging and more specifically for evaluation of head and neck (HN) cancer [4], PET/CT interpreters need to familiarize themselves with the image findings of $\mathrm{CN}$ involvement, which will greatly impact the staging and management of these patients.

Tumor related PET/CT findings include the perineural spread of HN tumors which represents a rare contiguous metastatic extension of tumor along a cranial nerve that portends to poor prognosis, even if the patient is asymptomatic $[2,5]$. If present, treatment can be changed to include neck dissection, a larger radiation field, or adding adjuvant therapy [6-8]. Facial nerve involvement (CN VII) in parotid tumors may preclude facial nervesparing surgery or require additional treatment modality [9]. Patients with skin cancer and perineural invasion will require adjuvant radiation therapy even when clear margins are achieved with Mohs surgery [10, 11]. Also

\footnotetext{
* Correspondence: oraslan@slu.edu

'Department of Radiology, Division of Nuclear Medicine, St Louis University, 3635 Vista Avenue, Saint Louis, MO 63110, USA

Full list of author information is available at the end of the article
}

the degree of FDG uptake by the tumor as measured by the SUV max is an important prognostic marker for locally advanced nasopharyngeal cancer. High FDG uptake reflects more aggressive tumors that may require more aggressive treatment and carries a worse prognosis, as compared to the less aggressive low FDG tumors [12].

Non-tumor related benign and malignant cranial nerve pathology can also be incidentally detected during PET/CT oncologic imaging including schwannomas [13], optic nerve glioma [14], meningioma [15], and melanoma [15]. Gallium 68 (68Ga) 1,4,7,10-tetraazacyclododecane-1,4,7,10tetraaceticacid (DOTA)-octreotate (DOTATATE, GaTate), has been shown to be more sensitive than FDG-PET/CT in detection of low grade somatostatin receptor positive tumors namely meningioma, esthesioneuroblastoma and schwannoma [16].

The purpose of this article is to describe the primary and secondary FDG-PET/CT findings of CN pathology and to provide a comprehensive illustration of the PET/ CT cross-sectional anatomy and pathology of almost each individual $\mathrm{CN}$, thus raising awareness and familiarity about incidental $\mathrm{CN}$ lesions seen on PET/CT, which will directly reflect on patient staging and management.

\section{Primary and secondary PET/CT findings of CN pathology}

The primary sign of $\mathrm{CN}$ pathology includes linear thickening or linear increased/decreased FDG activity along 


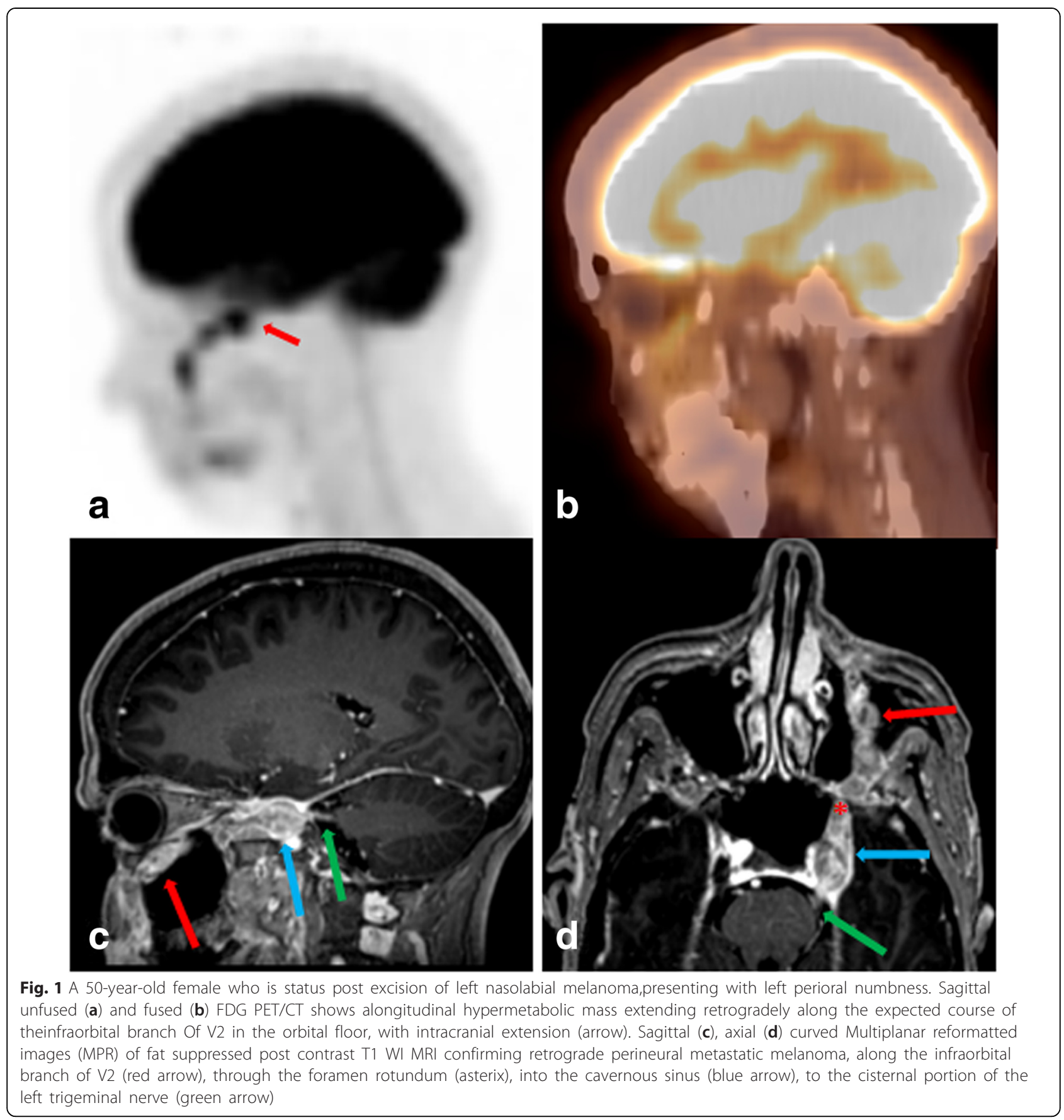

the expected course of the CN (Fig. 1). For this purpose, all three planes (axial, coronal and sagittal) and maximum intensity projection (MIP) images must be evaluated and correlations with all other available imaging modalities, e.g. (CT or MRI) which will often confirm the abnormality.

The secondary signs of $\mathrm{CN}$ pathology include widening or destruction at the corresponding skull base foramen, asymmetric atrophy or abnormal activity in the muscles supplied by the $\mathrm{CN}$, or increased FDG activity related to synergistic/antagonistic muscle overcompensation to maintain function (Table 1).

\section{Case presentation}

Olfactory nerve (CN I)

Direct visualization of the $\mathrm{CN}$ I lesion is beyond the resolution of $\mathrm{PET} / \mathrm{CT}$, however $\mathrm{CN}$ I involvement 
Table 1 Clinical, primary and secondary findings of CN pathology

\begin{tabular}{|c|c|c|c|c|c|}
\hline \multirow{3}{*}{$\begin{array}{l}\text { Symptoms/signs that } \\
\text { trigger search pattern for } \\
\text { CN pathology }\end{array}$} & \multirow[t]{3}{*}{ Which CN to suspect? } & \multicolumn{4}{|c|}{ What to look for and where to look for it on PET/CT? } \\
\hline & & \multirow{2}{*}{$\begin{array}{l}\text { Primary Sign } \\
\text { Abnormality along } \\
\text { course of CN }\end{array}$} & \multicolumn{3}{|l|}{ Secondary Signs } \\
\hline & & & $\begin{array}{l}\text { Abnormal skull } \\
\text { base foramen/ } \\
\text { bone }\end{array}$ & Muscle atrophy & Over compensation \\
\hline Anosmia & CN I (Olfactory) & $\begin{array}{l}\text { Roof of nose and } \\
\text { anterior cranial } \\
\text { fossa }\end{array}$ & $\begin{array}{l}\text { Cribriform plate of } \\
\text { ethmoid }\end{array}$ & - & - \\
\hline Visual loss & CN II (Optic) & $\begin{array}{l}\text { Orbit, suprasellar } \\
\text { cistern }\end{array}$ & Optic canal & - & - \\
\hline Diplopia & CN III (Oculomotor) & Cavernous sinus & $\begin{array}{l}\text { Superior orbital } \\
\text { fissure (SOF) }\end{array}$ & $\begin{array}{l}\text { Extraocular } \\
\text { muscles (except } \\
\text { superior oblique } \\
\text { and lateral rectus } \\
\text { muscles) }\end{array}$ & - \\
\hline Vertical diplopia & CN IV (Trochlear) & Cavernous sinus & SOF & Superior oblique & - \\
\hline Trigeminal Neuralgia & $\begin{array}{l}\mathrm{CN} \vee \text { (Trigeminal, } \\
\text { main trunk) }\end{array}$ & $\begin{array}{l}\text { Pons, prepontine } \\
\text { cistern, Meckel's } \\
\text { cave. }\end{array}$ & - & - & - \\
\hline $\begin{array}{l}\text { Paresthesia over forehead } \\
\text { and eye }\end{array}$ & $\begin{array}{l}\text { CN V1 (Ophthalmic } \\
\text { division) }\end{array}$ & Cavernous sinus & SOF & - & - \\
\hline Paresthesia over cheek & $\begin{array}{l}\text { CN V2 (Maxillary } \\
\text { division) }\end{array}$ & $\begin{array}{l}\text { Cavernous sinus, } \\
\text { cheek }\end{array}$ & $\begin{array}{l}\text { Foramen } \\
\text { rotundum, } \\
\text { pterygopalatine } \\
\text { fossa and } \\
\text { infraorbital canal } \\
\text { /foramen }\end{array}$ & - & - \\
\hline $\begin{array}{l}\text { Paresthesia over chin, } \\
\text { trismus }\end{array}$ & $\begin{array}{l}\text { CN V3 (Mandibular } \\
\text { division) }\end{array}$ & Masticator space & $\begin{array}{l}\text { Foramen ovale, } \\
\text { mandibular canal } \\
\text { and mental } \\
\text { foramen }\end{array}$ & - & - \\
\hline Lateral gaze diplopia & CN VI( Abducens) & $\begin{array}{l}\text { Cavernous sinus, } \\
\text { clivus }\end{array}$ & SOF & Lateral rectus & Ipsilateral Medial rectus \\
\hline Facial palsy & CN VII (Facial) & $\begin{array}{l}\text { Cerebellopontine } \\
\text { angle, parotid } \\
\text { space }\end{array}$ & $\begin{array}{l}\text { Petrous bone, } \\
\text { internal auditory } \\
\text { canal (IAC), and } \\
\text { stylomastoid } \\
\text { foramen }\end{array}$ & - & - \\
\hline Hearing loss/ imbalance & $\begin{array}{l}\text { CN VIII } \\
\text { (Vestibulocochlear) }\end{array}$ & $\begin{array}{l}\text { Cerebellopontine } \\
\text { angle }\end{array}$ & $\begin{array}{l}\text { Petrous bone and } \\
\text { IAC }\end{array}$ & - & - \\
\hline Hoarseness & $\begin{array}{l}\text { CN X (Vagus nerve, } \\
\text { recurrent laryngeal } \\
\text { branch) }\end{array}$ & Carotid space, & & & $\begin{array}{l}\text { tracheoesophageal } \\
\text { grooves, around aortic } \\
\text { root }\end{array}$ \\
\hline Jugular foramen (JF) & Ipsilateral vocal cord & $\begin{array}{l}\text { Contralateral vocal } \\
\text { cord }\end{array}$ & & & \\
\hline Shoulder drooping & $\begin{array}{l}\text { CN XI (Spinal } \\
\text { accessory) }\end{array}$ & Carotid space & $\begin{array}{l}\mathrm{JF} \text {, foramen } \\
\text { magnum }\end{array}$ & $\begin{array}{l}\text { Sternomastoid } \\
\text { and trapezius } \\
\text { muscles }\end{array}$ & - \\
\hline Dysarthria and dysphagia & $\begin{array}{l}\text { CN XII (Hypoglossal } \\
\text { nerve) }\end{array}$ & $\begin{array}{l}\text { occipital condyles } \\
\text {, Carotid space, } \\
\text { base of tongue }\end{array}$ & $\begin{array}{l}\text { JF, Hypoglossal } \\
\text { canal }\end{array}$ & $\begin{array}{l}\text { Ipsilateral } \\
\text { hemitongue }\end{array}$ & Contralateral hemitounge \\
\hline
\end{tabular}

should be suspected in lesions involving the superior sinonasal and anterior cranial fossa region. The differential considerations include olfactory neuroblastoma (Esthesioneuroblastoma), sinonasal carcinoma and melanoma (Fig. 2).

\section{Optic nerve (CN II)}

The main differential considerations for $\mathrm{CN}$ II lesion include optic pathway glioma (OPG), optic nerve sheath meningioma, idiopathic orbital inflammatory pseudotumor, and optic neuritis. FDG activity in Optic nerve glioma 

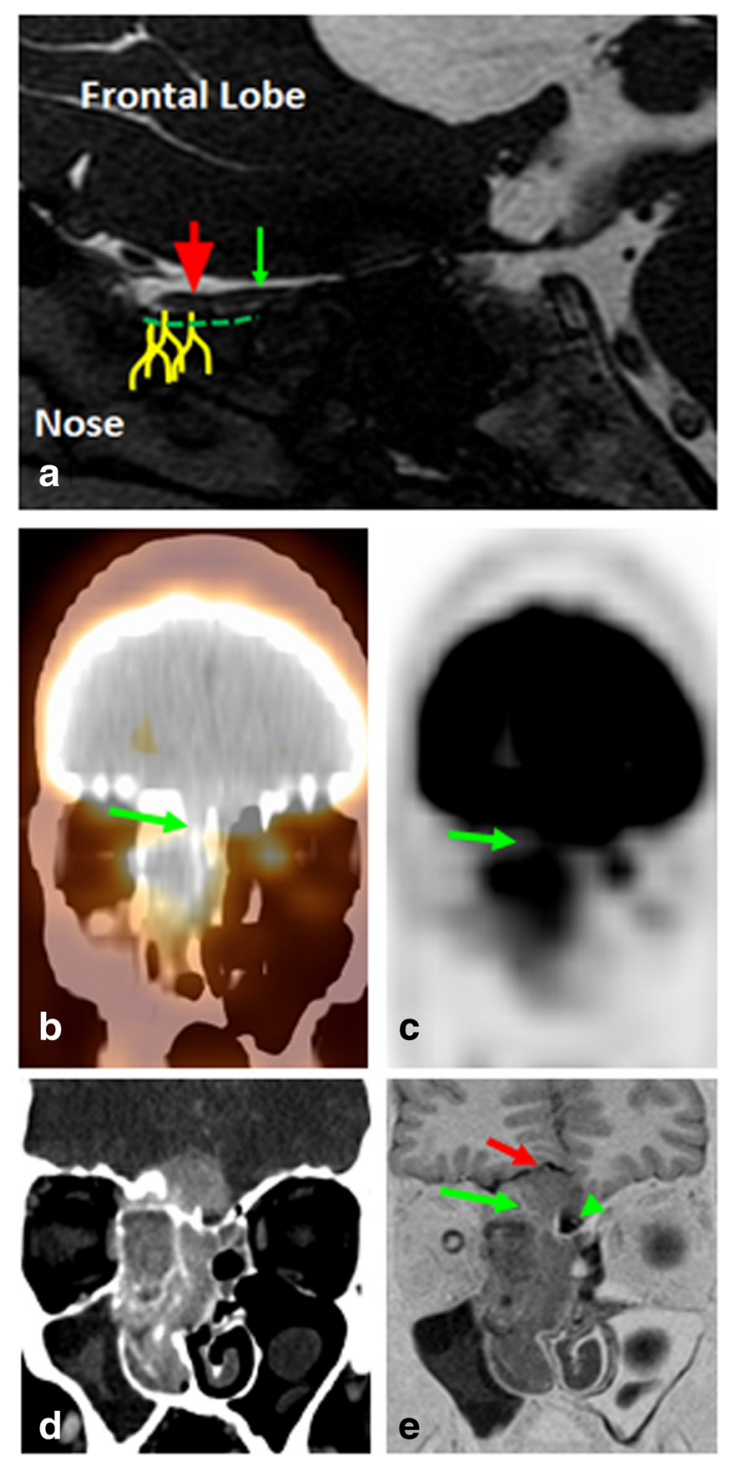

Fig. 2 a Sagittal steady state free precession (SSFP) MRI image of the brain showing the olfactory nerve anatomy: The fibers in the superior nasal mucosa (yellow fibers), ascend through the fenestrated cribriform plate of the ethmoid bone (green dashed line) to reach the

anteriorcranial fossa and continue as the olfactory bulb (red arrow) and tract (green arrow) coursing atthe inferior surface of the ipsilateral frontal lobe. b-e A 38-year-old male presented with a 6 month history of anosmia and episodic epiphoresis, nasal stuffiness. Coronal fused (a) andunfused (b) PET/CT images demonstrate a large aggressive

hypermetabolic mass centered on thesuperior aspect of the nasal cavity, extending superiorly into the right anterior cranial fossa andcribriform plate of ethmoid bone, involving the expected location of the right olfactorynerve/bulb/track (arrow). Our differential diagnosis was olfactory neuroblastoma (Esthesioneuroblastoma), or sinonasal carcinoma/ melanoma. Coronal contrast enhanced $\subset$ (c) demonstrate the enhancing mass extending into the anterior cranial fossa at the expected locationof CNI. Coronal short tau inversion recovery (STIR) (e) images confirm the intracranial extension (arrow) with involvement of the right olfactory nerve/bulb (red arrow). Note the normal left olfactory track (green arrowhead). Surgical pathology showed an olfactory neuroblastom

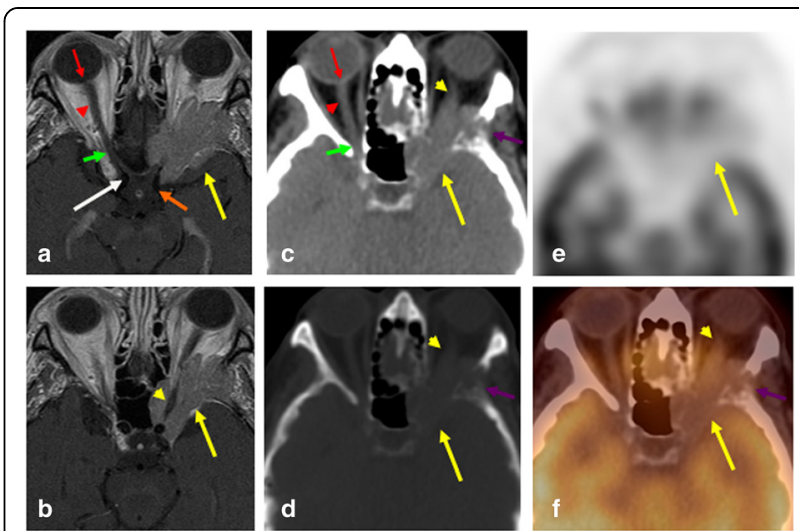

Fig. 3 A 74-year-old female complaining of double vision. Axial post contrast T1 WI MRI (a, b), The right optic nerve demonstrates the normal anatomy, showing the four segments of the optic nerve, the retinal (red arrow), orbital (arrow head), canalicular (green arrow) and cisternal parts (white arrow). The optic chiasm is also seen (orange arrow). On the left side, ahomogenously enhancing extra axial mass is seen centered on the eroded left greater wing of thesphenoid bone encasing the left optic nerve. Axial CT soft tissue (c) and bone windows (d), axialPET (e), and fused PET/CT (f) images, showing a hypometabolic soft tissue mass causinghyperostosis and erosion of the left greater wing of the sphenoid and extending into the orbitalcavity along the optic nerve. Diagnosis sphenoid wing meningioma with intra orbital extension,encasing the optic nerve

is variable depending on its histological grade [17, 18]. Some authors suggested the use of FDG-PET/CT in monitoring malignant transformation of OPG in children with neurofibromatosis type 1 syndrome [17, 19]. Optic meningioma is a benign tumor that typically demonstrate minimal to no FDG uptake on PET [15] and can be associated with bony sclerosis/destruction as in our case (Fig. 3). Orbital pseudotumor could be both hyper or isometabolic on FDG PET [18]. Xie et al. described a 56-year-old female with elevated FDG activity in several cranial and peripheral nerves suggestive of multiple neuritis, with patient"s symptoms improving following treatment [3].

\section{Oculomotor, trochlear and abducens nerves (CN III, IV, VI)}

Direct visualization of CNs III, IV and VI is usually beyond the resolution of PET/CT, however large brain stem or cavernous sinus lesions along the course of these nerves may indicate cranial nerve involvement by these lesions. Also, extraocular muscle atrophy or asymmetric decreased uptake could represent denervation injury, which should prompt a search for a lesion along the course of the innervating $\mathrm{CN}$. In an attempt to compensate for the paralyzed muscle, the non affected extraocular muscles may show increased FDG activity, further confirming the $\mathrm{CN}$ involvement (Fig. 4c-e). 

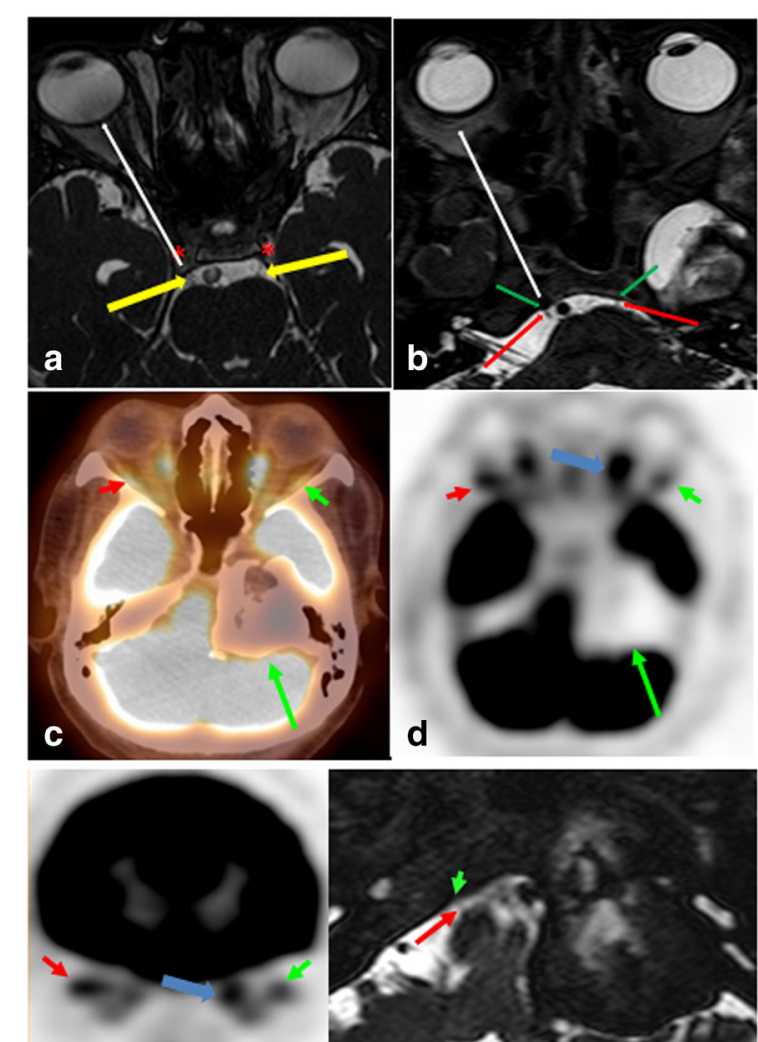

e

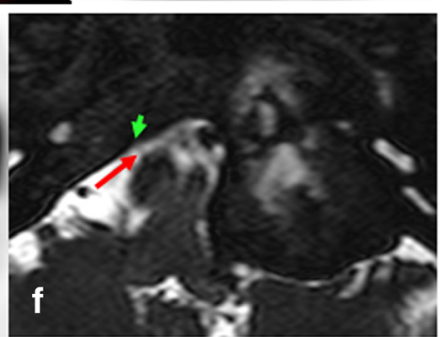

Fig. 4 Axial Fast imaging employing steady-state acquisition (FIESTA) MRI image (a) showing the CNIII (yellow arrows) entering the cavernous sinus (asterix). From here, CNIII courses anteriorly in the dura of the cavernous sinus to enter the orbit through the superior orbital fissure (SOF), supplying the extra ocular muscles except the superior oblique and lateral rectus muscles. Axial FIESTA MRI image (b) shows the normal abducens nerves (red arrow) entering Dorello's canal (green arrow). From here, CN VI courses anteriorly through the cavernous sinus to enter the orbit through the SOF, supplying the lateral rectus muscle. The white arrows show the general direction of travel of CN III and $\mathrm{VI}(\mathbf{a}, \mathbf{b})$. A 73-year-old male presenting complaining of double vision. Axial fused PET/CT (c), PET (d), and coronal PET (e) images showing a large peripherally ossified hypometabolic expansile mass centered in the left petrous apex extending to the cerebellopontine angle and middle cranial fossa (long green arrow). Note the lower activity in the left lateral rectus muscle (green short arrow) compared to the right one (red arrow) and the overcompensating hypermetabolic left medial rectus muscle, indicative of left abducens nerve paresis which was confirmed clinically. $\mathbf{f}$ Zoomed in Axial FIESTA MRI imaging shows the normal right abducens nerve (red arrow) entering Dorello's canal (green arrow). On the left side, the mass is seen involving the expected location of the left $\mathrm{CN}$ VI

\section{Trigeminal nerve, maxillary and mandibular divisions (CNV, V2 \& V3)}

FDG-PET/CT can detect perineural tumor spread along the trigeminal nerve and its main divisions; most

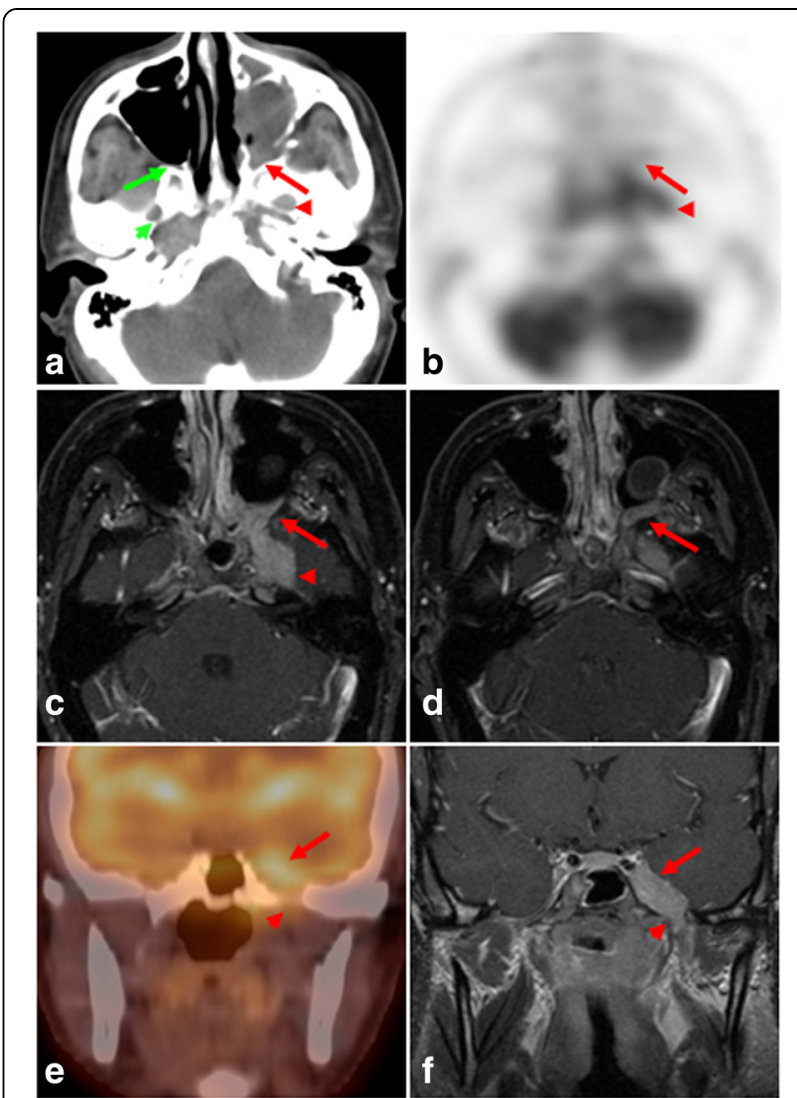

Fig. 5 A 41-year-old male with nasopharyngeal squamous cel carcinoma. Axial CT (a), and PET (b) images show an iso/hyperdense hypermetbolic mass extending into the enlarged left pterygopalatine fossa (red arrow) and foramen ovale (red arrowhead), confirming perineural tumor spread along the maxillary (V2) and mandibular (V3) divisions of the trigeminal (CNV) nerve. Note the normal appearance of the right pterygopalatine fossa (green arrow) and foramen ovale (green arrowhead). Axial contrast-enhanced fat suppressed T1 SI MR $(\mathbf{c}, \mathbf{d})$ of the neck confirm extension of the enhancing soft tissue mass from the left cavernous sinus/Meckel's cave region in to the left pterygopalatine fossa (red arrow). Coronal fused PET/CT (e) and contrast-enhanced fat suppressed T1 SI MR (f) confirming perineural extension of the tumor along $V_{3}$, infiltrating the left cavernous sinus/ Meckel's cave region (arrow) and widening the ipsilateral foramen ovale (arrowhead)

commonly arising from head and neck squamous cell carcinoma, adenoid cystic carcinoma, mucoepidermoid carcinoma, skin cancer and melanoma as well as [2] lymphoma [1] and neurolymphomatosis [20] (Fig. 5).

\section{Facial/ vestibulocochlear nerve complex (CNVII and VIII)}

The most common cerebellopontine angle lesions are vestibular schwannoma and meningioma. Vestibular schwannoma is typically described as a hypometabolic lesion [21], however in our experience they were 

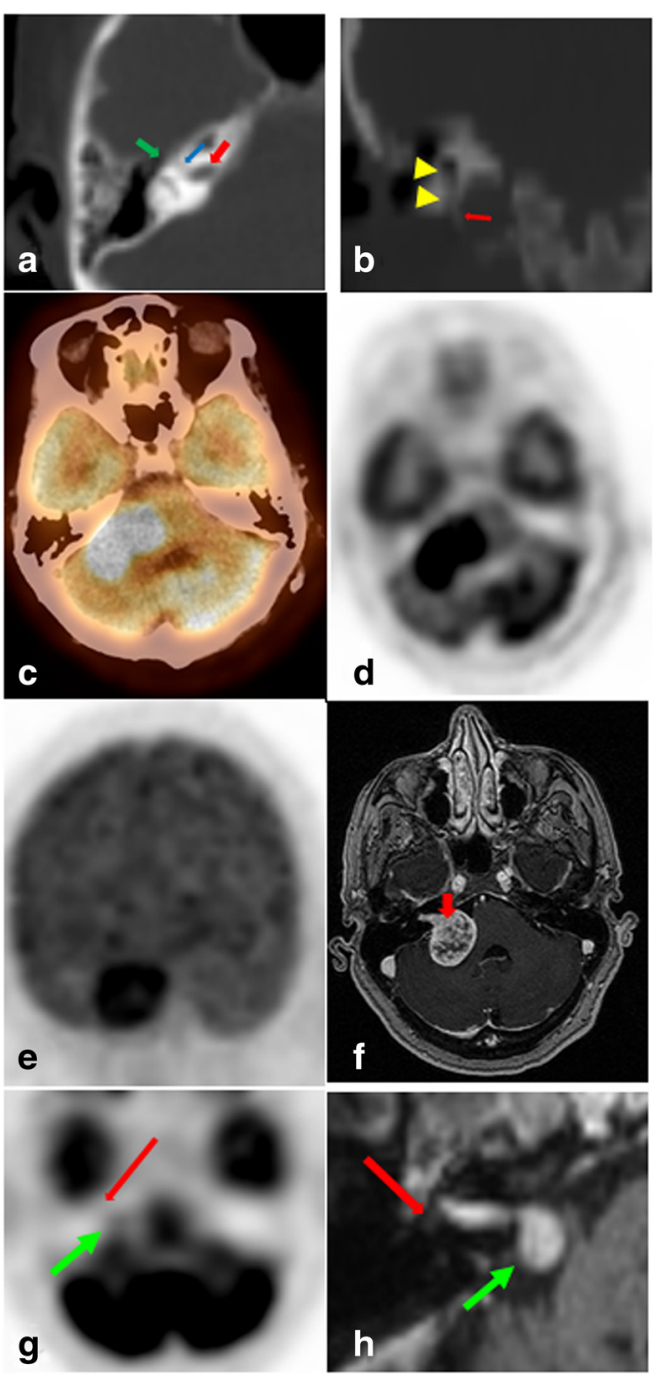

Fig. 6 Axial (a) and coronal (b) low resolution CT part of PET/CT. a On the axial view the internal auditory canal parts of CNVII and VIII (red arrow), as well as the labyrinthine (bluearrow) and tympanic parts (green arrow) of CN VII can be visualized. $\mathbf{b}$ On the coronal view,the styloid process (red arrow) can be used as a landmark to visualize the stylomastoid foramen,containing the stylomastoid part of CN VII (arrow heads). c-f A 62 year-old-female with rightsided hearing loss. Axial fused/non fused FDG PET/CT (c, d) and coronal Maximum Intensity projection (MIP) (e) images showing an intensely hypermetabolic right cerebellopontine angle lesion (CPA) lesion. Given patient history of hearing loss, this was consistent with vestibular schwannoma, rather than a meningioma. Axial contrast enhanced T1 WI MRI (f) showing the classic heterogeneously enhancing "ice cream cone" mass extending into the right internal auditory canal (IAC) (arrow), consistent with vestibular schwannoma, which was confirmed pathologically. g, h A 71-yearold female patient with history of worsening right sided hearing loss, unsteadiness, and neck pain. Axial unfused PET/CT images (g) and contrast enhanced T1 WI MRI (h) show a right CPA enhancing lesion with mild focal FDG activity (SUVmax 3.0) (green arrow), extending along the IAC, labyrinthine and tympanic segments of CN7 (red arrow) confirming that this is a facial nerve schwannoma rather than the more common vestibular nerve schwannoma hypermetabolic (Fig. 6c-f), which may be related to the large size of the lesions. Vestibular schwannoma is differentiated from meningioma by extension into the internal auditory canal (Fig. 6f). The less common facial nerve schwannoma is diagnosed when the lesion extends along the labyrinthine segment of CNVII (Fig. 6g, h). Perineural spread form parotid gland lesions should be suspected with abnormal activity extending superiorly along the stylomastoid foramen or within the temporal bone [2, 22, 23]. Rare CN melanoma metastasis along CNs VII and VIII has also been described [24].

\section{Vagus and spinal accessory nerves (CNs X and XI)}

The most common jugular foramen (JF) lesions that my involve CN X and XI are glomus juglare, schwannoma, meningioma and skull base metastasis. Looking at the bone margins of the JF on the bone window of PET/CT may help differentiate glomus tumors which tend to have a permeative destructive margins from schwannoma which tend to cause smooth expansion of the JF (Fig. 7e) and meningioma, which may have permeative sclerotic margins [25]. If the recurrent laryngeal branch of CNX is involved, it will be seen as a hypometabolic ipsilateral paralyzed vocal cord with a hypermetabolic overcompensating contralateral vocal cord (Fig. 7c, d). Ipsilateral shoulder dropping on MIP images (Fig. 7g), with atrophy of the trapezius and sternomastoid muscles on the axial images (Fig. 7c, d), signifies CNXI involvement, which could be secondary to CNXI sacrifice during neck dissection.

\section{Hypoglossal nerve (CN XII)}

Injury of CNXII could occur by the aforementioned JF lesions [25]. Further distally it could be secondary to hypoglossal foramen lesions (CNXII Schwannoma [25, 26]), clival tumor (chordoma, chondrosarcoma and plasmacytoma) [25], or rarely could be secondary to retrospective perineural tumor spread from tongue base tumor or radiation injury. An atrophic sagging fatty infiltrated ipsilateral tongue will be seen with hypometabolism on PET/CT (Fig. 8 b, d, e) [25].

\section{Conclusion}

Cranial nerve pathology can be detected on FDG PET/CT. With the increased reliance on $\mathrm{PET} / \mathrm{CT}$ in patient staging and follow-up, PET/CT interpreters should familiarize themselves with these findings as it may change patient staging and management.

\section{Consent}

"This retrospective study was approved by the Saint Louis University IRB board". 

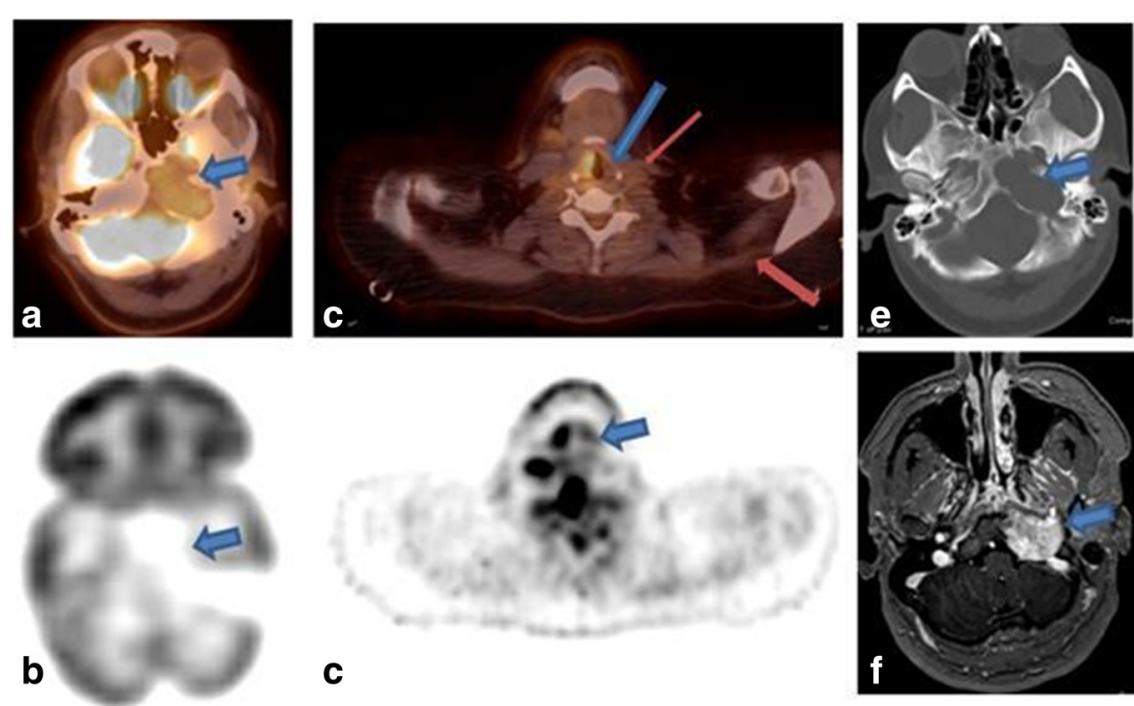

C
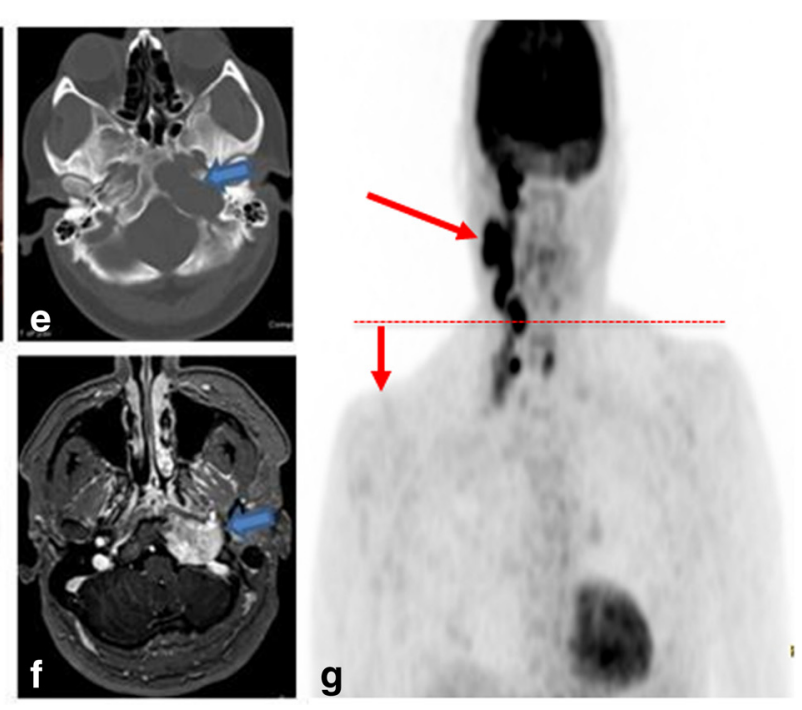

Fig. 7 A 32 year-old-female presenting with a hoarse voice. Axial fused (a) and unfused (b) PET/CT images of the skull base showing a hypometabolic soft tissue mass centered on the left jugular foramen with smooth osseous expansion suggestive of schwannoma of cranial nerve IX, X or XI which all exit the skull base through the jugular foramen. Axial fused (c) and unfused (d) PET/CT images at the level of the glottis show no 18F-FDG uptake in the left vocal cord (blue arrow) with compensatory increased activity in the right vocal cord, consistent with laryngoscopy proven left vocal cord paralysis due to tumor involvement of left CN X and its recurrent laryngeal branch. Asymmetric atrophy of the left sternomastoid and trapezius muscles is consistent with chronic denervation due to tumor involvement of the left cranial nerve XI (spinal accessory nerve) (red arrows). Axial CT scan of the skull base with bone window settings (e) and axial post-contrast fat-suppressed T1 MRI (f) at the same level show the enhancing left cranial nerve IX/X/XI mass pathologically proven to be a schwannoma. $\mathbf{g}$ Coronal MIP image of a 50year-old male with HIV presenting with worsening right facial weakness and pathologically proven squamous cell carcinoma of the neck, with perineural tumor invasion along the jugular foramen (not shown), showing right shoulder drooping compared to the left one (red line), secondary to atrophy of the right trapezius and sternomastoid muscles, confirmingCN XI involvement. Also note the bulky hypermetabolic cervical adenopathy (arrow) in the rightneck involving lymph node levels 1 through 4 consistent with metastatic lymph nodes

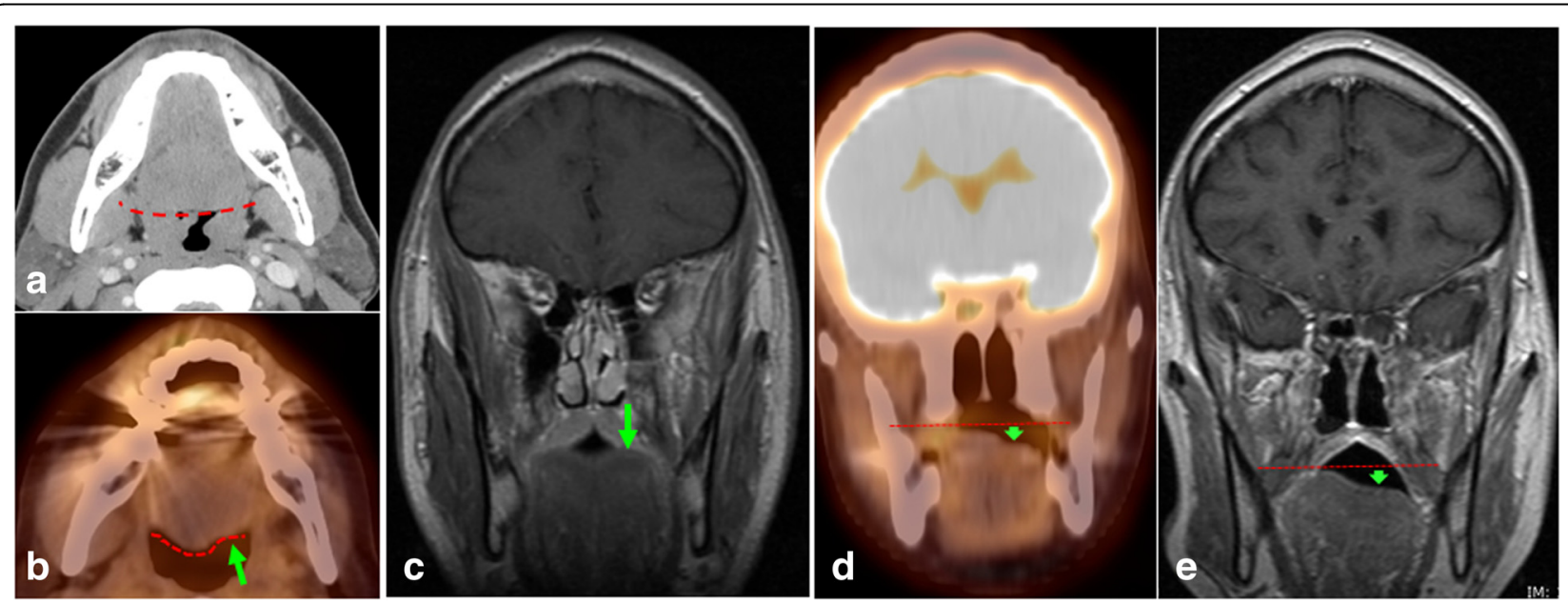

Fig. 8 A 41 year-old-male patient diagnosed with left sided nasopharyngeal carcinoma and intracranial involvement. Axial CT of the neck (a) at the time of diagnosis (5/2005) showing normal posterior contour of the tongue (red line). The patient received radiotherapy and chemotherapy ending in 2006. Follow-up axial fused PET/CT images of the neck region (b) on (8/2013) shows interval atrophy of the left hemi-tongue, with abnormal posterior contour (green line). Post contrast coronal T1 WI before treatment (c), coronal fused PET/CT and coronal contrast enhanced MRI TIW images after treatment (d, e) confirming the left hemi tongue atrophy (arrow). Clinically, the patients tongue deviates to the left. The constellation of findings is consistent with post radiation hypoglossal neuropathy 


\section{Abbreviations}

FDG: [18 F]-2- deoxy-D-glucose; PET/CT: Positron emission tomography with computerized tomography; CN: Cranial nerve; HN: Head and neck; CPA: Cerebellopontine angle lesion; IAC: Internal auditory canal; JF: Jugular foramen; CN I: Olfactory nerve; CN II: Optic nerve; CN III: Oculomotor nerve; CN IV: Trochlear nerve; CN V: Trigeminal nerve; CN V1: Ophthalmic division of trigeminal nerve; CN V2: Maxillary division of trigeminal nerve; $C N$ V3: Mandibular division of trigeminal nerve; CN VI: Abducens nerve; $\mathrm{CN}$ VII: Facial nerve; CN VIII: Vestibulocochlear nerve; CN IX: Glossopharyngeal nerve; CN X: Vagus nerve; CN XI: Spinal accessory nerve; CN XII: Hypoglossal nerve; FIESTA: Fast imaging employing steady-state acquisition; MPR: Multiplanar reformatted images; SSFP: Steady state free precession; STIR: Short tau inversion recovery; MIP: Maximum intensity projection.

\section{Competing interests}

Dr. Osman: Speaker, Koninklijke Philips NV. All other authors have no financial disclosures.

\section{Authors' contributions}

All Authors: 1) Have made substantial contributions to conception and design, or acquisition of data, or analysis and interpretation of data; 2) have been involved in drafting the manuscript or revising it critically for important intellectual content; 3) have given final approval of the version to be published; and 4) agree to be accountable for all aspects of the work in ensuring that questions related to the accuracy or integrity of any part of the work are appropriately investigated and resolved. All authors read and approved the final manuscript.

\section{Acknowledgment}

None.

\section{Author details}

Department of Radiology, Division of Nuclear Medicine, St Louis University, 3635 Vista Avenue, Saint Louis, MO 63110, USA. ²Department of Radiology, Division of Neuroradiology, St Louis University, 3635 Vista Avenue, Saint Louis, MO 63110, USA.

\section{Received: 30 July 2015 Accepted: 4 November 2015}

\section{Published online: 03 December 2015}

\section{References}

1. Yılmaz S, Sağer S, Sen F, Halac M. Bilateral trigeminal nerve recurrence of non-hodgkin lymphoma revealed with FDG PET/CT. Indian J Nucl Med. 2014;29(1):50-2.

2. Paes FM, Singer AD, Checkver AN, Palmquist RA, De La Vega G, Sidani C. Perineural spread in head and neck malignancies:clinical significance and evaluation with 18F-FDG PET/CT. Radiographics. 2013;33(6):1717-36.

3. Xie $X$, Cheng B, Han X, Liu B. Findings of multiple neuritis on FDG PET/CT imaging. Clin Nucl Med. 2013;38(1):67-9.

4. Pfister DG, Ang KK, Brizel DM, Burtness BA, Busse PM, Caudell J, et al. Head and neck cancers, version 2.2013. Featured updates to the NCCN guidelines. J Natl Compr Canc Netw. 2013;11(8):917-23.

5. Liebig C, Ayala G, Wilks JA, Berger DH, Albo D. Perineural invasion in cancer: a review of the literature. Cancer. 2009;115(15):3379-91.

6. Salamaa J, Sabab N, Quonc H, Gargd M, Lawsone J, McDonaldf M, et al. ACR appropriateness criteria ${ }^{\oplus}$ adjuvant therapy for resected squamous cell carcinoma of the head and neck. Oral Oncol. 2011;47(7):554-9.

7. Tai SK, Li WY, Yang MH, Chang SY, Chu PY, Tsai TL, et al. Treatment for T1-2 oral squamous cell carcinoma with or without perineural invasion: neck dissection and postoperative adjuvant therapy. Ann Surg Oncol. 2012;19(6): 1995-2002.

8. Chatterjee S, Frew J, Mott J, McCallum H, Stevenson P, Maxwell R, et al. Variation in radiotherapy target volume definition, dose to organs at risk and clinical target volumes using anatomic (computed tomography) versus combined anatomic and molecular imaging (positron emission tomography/computed tomography): intensity-modulated radiotherapy delivered using a tomotherapy Hi Art machine: final results of the VortigERN study. Clin Oncol (R Coll Radiol). 2012;24(10):e173-9.

9. Bell RB, Dierks EJ, Homer L, Potter BE. Management and outcome of patients with malignant salivary gland tumors. J Oral Maxillofac Surg. 2005;63(7):917-28.
10. Warren TA, Panizza B, Porceddu SV, Gandhi M, Patel P, Wood M, et al. Outcomes after surgery and postoperative radiotherapy for perineural spread of head and neck cutaneous squamous cell carcinoma. Head Neck. 2014 Dec 24. doi: 10.1002/hed.23982. [Epub ahead of print] PubMed PMID: 25546817.

11. Dunn M, Morgan MB, Beer TW. Perineural invasion: identification, significance, and a standardized definition. Dermatol Surg. 2009;35(2):214-21.

12. Xie P, Yue JB, Fu Z, Feng R, Yu JM. Prognostic value of 18F-FDG PET/CT before and after radiotherapy for locally advanced nasopharyngeal carcinoma. Ann Oncol. 2010;21(5):1078-82. doi:10.1093/annonc/mdp430. Epub 2009 Nov 13

13. Jung EJ, Han HS, Koh YC, Cho J, Ryu CG, Paik JH, et al. Metachronous schwannoma in the colon with vestibular schwannoma. Ann Surg Treat Res. 2014;87(3):161-5.

14. Roselli F, Pisciotta NM, Aniello MS, Niccoli-Asabella A, Defazio G, Livrea P, et al. Brain F-18 Fluorocholine PET/CT for the assessment of optic pathway glioma in neurofibromatosis-1. Clin Nucl Med. 2010;35(10):838-9.

15. Muzaffar R, Shousha MA, Sarajlic L, Osman MM. Ophthalmologic abnormalities on FDG-PET/CT: a pictorial essay. Cancer Imaging. 2013;13:100-12.

16. Hofman MS, Lau WF, Hicks RJ. Somatostatin receptor imaging with $68 \mathrm{Ga}$ DOTATATE PET/CT: clinical utility, normal patterns, pearls, and pitfalls in interpretation. Radiographics. 2015;35(2):500-16.

17. Moharir M, London K, Howman-Giles R, North K. Utility of positron emission tomography for tumour surveillance in children with neurofibromatosis type 1. Eur J Nucl Med Mol Imaging. 2010;37(7):1309-17.

18. Miyamoto J, Tatsuzawa K, Owada K, Kawabe T, Sasajima H, Mineura K. Usefulness and limitations of fluorine-18-fluorodeoxyglucose positron emission tomography for the detection of malignancy of orbital tumors. Neurol Med Chir (Tokyo). 2008;48(11):495-9. discussion 499.

19. Mölenkamp G, Riemann B, Kuwert T, Sträter R, Kurlemann G, Schober O, et al. Monitoring tumor activity in low grade glioma of childhood. Klin Padiatr. 1998;210(4):239-42.

20. Salm LP, Van der Hiel B, Stokkel MP. Increasing importance of 18F-FDG PET in the diagnosis of neurolymphomatosis. Nucl Med Commun. 2012;33(9):907-16.

21. Ginsberg LE. Imaging of perineural tumor spread in head and neck cancer. Semin Ultrasound CT MR. 1999;20(3):175-86.

22. Nemec SF, Herneth AM, Czerny C. Perineural tumor spread in malignant head and neck tumors. Top Magn Reson Imaging. 2007;18(6):467-71.

23. Lopci E, Monti L, Balzarini L, Chiti A. Cardiac and acoustic metastases in relapsing melanoma. Clin Nucl Med. 2013;38(2):e85-8.

24. Macdonald AJ, Salzman KL, Harnsberger HR, Gilbert E, Shelton C. Primary jugular foramen meningioma: imaging appearance and differentiating features. AJR Am J Roentgenol. 2004;182(2):373-7.

25. Thompson EO, Smoker WR. Hypoglossal nerve palsy: a segmental approach. Radiographics. 1994;14(5):939-58.

26. Santarius T, Dakoji S, Afshari FT, Raymond FL, Firth HV, Fernandes HM, et al. Isolated hypoglossal schwannoma in a 9-year old child. J Neurosurg Pediatr. 2012;10(2):130-3.

\section{Submit your next manuscript to BioMed Central and take full advantage of:}

- Convenient online submission

- Thorough peer review

- No space constraints or color figure charges

- Immediate publication on acceptance

- Inclusion in PubMed, CAS, Scopus and Google Scholar

- Research which is freely available for redistribution 